\title{
ELECTRON-ION RECOMBINATION RATE COEFFICIENTS AND PHOTOIONIZATION CROSS SECTIONS FOR ASTROPHYSICALLY ABUNDANT ELEMENTS. VII. RELATIVISTIC CALCULATIONS FOR O VI AND O VII FOR ULTRAVIOLET AND X-RAY MODELING
}

\author{
Sultana N. Nahar and Anil K. Pradhan \\ Department of Astronomy, Ohio State University, Columbus, OH 43210; nahar@astronomy.ohio-state.edu \\ Received 2003 April 1; accepted 2003 June 17
}

\begin{abstract}
Aimed at ionization balance and spectral analysis of UV and X-ray sources, we present self-consistent sets of photoionization cross sections, recombination cross sections, and rate coefficients for photoionization of, and recombination to, Li-like $\mathrm{O}$ VI and He-like $\mathrm{O}$ viI. Relativistic fine structure is considered through the Breit-Pauli $\boldsymbol{R}$-matrix (BPRM) method in the close-coupling approximation, implementing the unified treatment for total electron-ion recombination subsuming both radiative and dielectronic recombination processes. Self-consistency is ensured by using an identical wave function expansion for the inverse processes of photoionization and photorecombination. Radiation damping of resonances, important for $\mathrm{H}$-like and He-like core ions, is included. Compared with our previous $L S$ coupling results without radiative decay of low- $n(n \leq 10)$ resonances, the presents results show significant reduction in $\mathrm{O}$ vi recombination rates at high temperatures. In addition to the total rates, level-specific photoionization cross sections and recombination rates are presented for all fine-structure levels $n$ ( $l \mathrm{SLJ})$ up to $n \leq 10$, to enable accurate computation of recombination-cascade matrices and spectral formation of prominent UV and X-ray lines such as the 1032, $1038 \AA$ doublet of O VI, and the "triplet" forbidden, intercombination, and resonance X-ray lines of O VII at 22.1, 21.8, and $21.6 \AA$, respectively. Altogether, atomic parameters for 98 levels of $\mathrm{O}$ vI and 116 fine-structure levels of $\mathrm{O}$ VII are theoretically computed. These data should provide a reasonably complete set of photoionization and recombination rates in collisional or radiative equilibrium.
\end{abstract}

Subject headings: atomic data — atomic processes — line: formation — X-rays: general

\section{INTRODUCTION}

Li-like and He-like oxygen are among the most important atomic species in UV and X-ray plasma diagnostics of astrophysical sources. For example, there is considerable current interest in $\mathrm{O}$ VI and $\mathrm{O}$ VII as a possible reservoir of " missing baryons" in the warm/hot intergalactic medium in the present universe (Cen et al. 2001; Fang \& Canizares 2000; Yoshikawa et al. 2003). In addition to global ionization balance models that require $\mathrm{O}$ VI/O vII photoionization and recombination rates, specific spectroscopic diagnostics of both of these ions are related in an interesting but intricate manner. Outflows observed from the "warm absorber" in active galactic nuclei exhibit absorption/emission lines in the X-ray from KLL resonant photoabsorption in O vI, and excitation/recombination of $\mathrm{O}$ VII lines. This phenomenon was investigated theoretically by Pradhan (2000), who pointed out that the observed spectra of the wel- known active galactic nucleus NGC 5548 shows these features (Kaastra et al. 2000). Recently, Arav et al. (2003) have further pursued this suggestion to infer large discrepancies in the UV and X-ray O vi column densities in the outflow from NGC 5548. Ionization balance and spectral formation of $\mathrm{O}$ VI and $\mathrm{O}$ VII are crucial factors in all such studies.

The inverse atomic processes of photoionization and electron-ion photorecombination of Li-like and He-like ions are also of particular interest in X-ray astronomy to analyze new observations by space-based observatories such as the Chandra X-Ray Observatory and XMM-Newton, at photon energies and temperatures prevalent in hightemperature sources such as AGB, supernova remnants, hot stellar coronae, etc. (e.g., Canizares et al. in Bautista,
Kallman, \& Pradhan 2000). X-ray emission in the K $\alpha$ complex comprising of the "triplet" feature of resonance $(w)$, intercombination $(x, y)$, and forbidden $(z)$ lines in He-like ions, corresponding to the four transitions from the $n=2$ levels to the ground level $1 s^{2}\left({ }^{1} S_{0}\right) \longleftarrow 1 s 2 p\left({ }^{1} P_{1}^{o}\right)$, $1 s 2 p\left({ }^{3} P_{2,1}^{o}\right), 1 s 2 s\left({ }^{3} S_{1}\right)$, respectively, yields valuable spectral diagnostics of temperature, density, ionization balance, and abundances in the plasma source. Calculations of the recombination-cascade contributions for these important lines requires accurate atomic parameters for fine-structure levels up to fairly high $n$ levels, as presented in this report.

In the present work we report new results for selfconsistent data sets for photoionization and recombination for $(e+\mathrm{O}$ VII $) \longleftrightarrow \mathrm{O} \mathrm{VI}+h \nu$ and $(e+\mathrm{O}$ VIII $) \longleftrightarrow \mathrm{O}$ VII + $h \nu$, using a unified theoretical method that takes account of both radiative and dielectronic recombination processes (RR and DR). Although treated separately in other previous treatments, both recombination processes, $R R$ and $\mathrm{DR}$, are inseparable in nature. A unified treatment is therefore not only theoretically and computationally more accurate, it is also more suitable for many applications since a single recombination rate coefficient takes account of both RR and DR in an ab initio manner. For highly charged ions it is important to consider relativistic fine structure explicitly in the theoretical formulation, in addition to the electron correlation effects. Previous results for O VI (Nahar 1998, 1999) were obtained in a nonrelativistic $L S$ coupling approximation; relativistic effects were partially included for $\mathrm{O}$ vII. To further improve the accuracy, as well as to provide extensive sets of data for astrophysical models, we have recalculated all photoionization cross sections, electron-ion recombination cross sections, and rate coefficients using the 
relativistic Breit-Pauli $\boldsymbol{R}$-matrix (BPRM) method. Similar calculations have previously been reported for He- and Li-like ions C v and C Iv (Nahar et al. 2000), and Fe Xxv and Fe xxv (Nahar et al. 2001).

\section{THEORY}

The unified method of electron-ion recombination (Nahar \& Pradhan 1992) yields self-consistent sets of atomic parameters for photoionization and recombination for atoms and ions (e.g., Nahar \& Pradhan 1997, hereafter Paper I). Relativistic extension using the BPRM method is described in Zhang \& Pradhan (1997a), Pradhan \& Zhang (1997), and Zhang et al. (1999). Photorecombination of an incident electron with the target ion may occur through (i) nonresonant, background continuum, or radiative recombination (RR),

$$
e+\mathrm{X}^{++} \rightarrow h \nu+\mathrm{X}^{+},
$$

which is the inverse process of direct photoionization, or (ii) through a two-step recombination process via autoionizing resonances, i.e., dielectronic recombination (DR):

$$
e+\mathrm{X}^{++} \rightarrow\left(\mathrm{X}^{+}\right)^{* *} \rightarrow\left\{\begin{array}{c}
\text { (i) } e+\mathrm{X}^{++} \\
\text {(ii) } h \nu+\mathrm{X}^{+}
\end{array}\right\}
$$

where the quasi-bound doubly excited autoionizing state may lead either to (i) autoionization, a radiationless transition to a lower target state with the electron going into a continuum, or (ii) radiative stabilization to a recombined bound state via decay of the ion core (usually to the ground state) with the electron captured.

The extension of the $\boldsymbol{R}$-matrix method to electron-ion recombination calculations entails close-coupling calculations for photoionization and electron-ion scattering. Identical eigenfunction expansion for the target (core) ion is employed for both processes, enabling inherently selfconsistent results in an ab initio manner for a given ion. We consider photoionization from, and recombination into the infinity of levels of the $(e+$ ion $)$ system. These are divided into two groups of bound levels: (group A) with $\nu \leq \nu_{o}$ and all possible fine-structure $J \pi$ symmetries, and (group B) $\nu_{o}<\nu \leq \infty$, where $\nu$ is the effective quantum number relative to the target threshold(s). Photoionization and recombination calculations are carried out in detail for all group A levels, while group B levels are treated through quantum defect theory of DR within the close-coupling approximation (Bell \& Seaton 1985; Nahar \& Pradhan 1994). A generally valid approximation made in recombination to group B levels is that the background contribution is negligible and $\mathrm{DR}$ is the dominant process in the region below the threshold of convergence for high- $n$ resonances.

In the close-coupling (CC) approximation, the target ion (core) is represented by an $N$-electron system. The total wave function, $\Psi(E)$, of the $(N+1)$ electron-ion system of symmetry $J \pi$ is represented in terms of an expansion of target eigenfunctions as

$$
\Psi(E)=A \sum_{i} \chi_{i} \theta_{i}+\sum_{j} c_{j} \Phi_{j},
$$

where $\chi_{i}$ is the target wave function in a specific level $J_{i} \pi_{i}$ and $\theta_{i}$ is the wave function for the $(N+1)$-th electron in a channel labeled as $S_{i} L_{i}\left(J_{i}\right) \pi_{i} k_{i}^{2} l_{i}(J \pi) ; k_{i}^{2}$ being its incident kinetic energy. The quantities $\Phi_{j}$ are the correlation functions of the $(N+1)$-electron system that account for short-range correlation and the orthogonality between the continuum and the bound orbitals. In relativistic BPRM calculations the set of $S L \pi$ are recoupled for $J \pi$ levels of $(e+$ ion)-system, followed by diagonalization of the Hamiltonian,

$$
H_{N+1}^{\mathrm{BP}} \Psi=E \Psi
$$

where the BP Hamiltonian is

$$
H_{N+1}^{\mathrm{BP}}=H_{N+1}^{\mathrm{NR}}+H_{N+1}^{\mathrm{mass}}+H_{N+1}^{\mathrm{Dar}}+H_{N+1}^{\mathrm{so}} .
$$

The first term, $H_{N+1}^{\mathrm{NR}}$, is the nonrelativistic Hamiltonian,

$$
H_{N+1}^{\mathrm{NR}}=\sum_{i=1}^{N+1}\left\{-\nabla_{i}^{2}-\frac{2 Z}{r_{i}}+\sum_{j>i}^{N+1} \frac{2}{r_{i j}}\right\},
$$

and the additional one-body terms are the mass correction term,

$$
H^{\text {mass }}=-\left(\alpha^{2} / 4\right) \sum_{i} p_{i}^{4}
$$

the Darwin term,

$$
H^{\text {Dar }}=\left(Z \alpha^{2} / 4\right) \sum_{i} \nabla^{2}\left(1 / r_{i}\right)
$$

and the spin-orbit interaction term,

$$
H^{\mathrm{so}}=Z \alpha^{2} \sum_{i}\left(1 / r_{i}^{3}\right) \boldsymbol{l}_{i} \cdot \boldsymbol{s}_{i},
$$

respectively.

The positive and negative energy states (eq. [4]) define continuum or bound $\left(e+\right.$ ion) states, such that, $E=k^{2}>0$ for continuum (scattering) channels and $E=-\left(z^{2} / \nu^{2}\right)<0$ for bound states, where $\nu$ is the effective quantum number relative to the core level. If $E<0$, then all continuum channels are "closed" and the solutions represent bound states. The reduced matrix element for the bound-free transition, $\left\langle\Psi_{B}|| \boldsymbol{D} \| \Psi_{F}\right\rangle$, can be obtained from the continuum wave function $\left(\Psi_{F}\right)$ and the bound wave function $\left(<\Psi_{B}\right)$, where $\boldsymbol{D}$ is the dipole operator; $\boldsymbol{D}_{L}=\sum_{i} r_{i}$, in length form and $D_{V}=-2 \sum_{i} \Delta_{i}$ in velocity form, the sum being the number of electrons.

Photoionization cross sections of all possible states with $n \leq n_{\max } \sim 10$ are obtained as in the CC approximation as in the Opacity Project (Seaton 1987; The Opacity Project Team 1995, 1997), extended to include the relativistic effects under the Iron Project (Hummer et al. 1993). The photoionization cross section is obtained as

$$
\sigma_{P I}=\frac{1}{g} \frac{4 \pi^{2}}{3 c} \omega \boldsymbol{S}
$$

where $g$ is the statistical weight factor of the bound state and $\boldsymbol{S}$ is the dipole line strength, $\boldsymbol{S}=\left|\left\langle\Psi_{B}|| \boldsymbol{D}|| \Psi_{F}\right\rangle\right|^{2}$. For highly charged $\mathrm{H}$ - and the He-like ions, the probability of radiation decay of an autoionizing state is usually comparable to that of autoionization as discussed in Nahar et al. (2000). With strong dipole allowed $2 p \longrightarrow 1 s$ and $1 s 2 p\left({ }^{1} P_{1}^{o}\right) \longrightarrow$ $1 s^{2}\left({ }^{1} S_{0}\right)$ transitions autoionizing resonances are radiatively damped to a significant extent. The radiative damping effect of all near-threshold resonances, up to $\nu \leq 10$, is included using a resonance fitting procedure (Sakimoto et al. 1990; Pradhan \& Zhang 1997a; Zhang et al. 1999). 
The photorecombination cross section, $\sigma_{\mathrm{RC}}$, is related to the photoionization cross section, $\sigma_{\mathrm{PI}}$, through the principle of detailed balance (Milne relation) as

$$
\sigma_{\mathrm{RC}}(\epsilon)=\frac{\alpha^{2}}{4} \frac{g_{i}}{g_{j}} \frac{(\epsilon+I)^{2}}{\epsilon} \sigma_{\mathrm{PI}}
$$

in rydberg units; $\alpha$ is the fine-structure constant, $\epsilon$ is the photoelectron energy, and $I$ is the ionization potential. Values of $\sigma_{\mathrm{RC}}$ are computed from the photoionization cross sections at a sufficiently large number of energies to delineate the nonresonant background and the autoionizing resonances, thereby representing both radiative and the dielectronic recombination ( $R R$ and $\mathrm{DR}$ ) processes. In the unified treatment the photoionization cross sections, $\sigma_{\mathrm{PI}}$, of a large number of low- $n$ bound states - all possible states with $n \leq n_{\max } \sim 10$-are obtained as described above. It is assumed that the recombining ion is in the ground state, and recombination can take place into the ground or any of the excited recombined $(e+$ ion) states.

Recombination rate coefficients of individual levels are obtained by convolving recombination cross sections over a Maxwellian electron distribution $f(v)$ at a given temperature

$$
\alpha_{\mathrm{RC}}(T)=\int_{0}^{\infty} v f(v) \sigma_{\mathrm{RC}} d v .
$$

Contribution of these low- $n$ group A bound states to the total $\sigma_{\mathrm{RC}}$ is obtained by summing over all low- $n$ group A states. $\sigma_{\mathrm{RC}}$ thus obtained from $\sigma_{\mathrm{PI}}$, including the radiatively damped autoionizing resonances (eq. [8]), corresponds to the total $(\mathrm{DR}+\mathrm{RR})$ unified recombination cross section.

Recombination into the high- $n$ states, $n_{\max }<n \leq \infty$, (Fig. 1 of Nahar \& Pradhan 1994) are included separately. To each excited threshold of the core, $J_{i} \pi_{i}$, belongs an infinite series of $(N+1)$-electron levels, $J_{i} \pi_{i} \nu l$, to which recombination can occur. For the high- $\nu$ levels, DR dominates while the background RR is small and DR dominates the total recombination. The contributions from these levels are added by calculating the DR collision strengths, $\Omega_{\mathrm{DR}}$, employing the precise theory of radiation damping by Bell \& Seaton (1985) as extended by Nahar \& Pradhan (1994). The recombination cross section, $\sigma_{\mathrm{RC}}$ in megabarns $(\mathrm{Mb})$, is related to the collision strength, $\Omega_{\mathrm{RC}}$, as

$$
\sigma_{\mathrm{RC}}(i \rightarrow j)(\mathrm{Mb})=\pi \Omega_{\mathrm{RC}}(i, j) /\left(g_{i} k_{i}^{2}\right)\left(a_{0}^{2} / 10^{-18}\right),
$$

where $k_{i}^{2}$ is the incident electron energy in rydbergs. As $\sigma_{\mathrm{RC}}$ diverges at zero-photoelectron energy, the total collision strength, $\Omega$, is used in the recombination rate calculations.

The small background (nonresonant) contribution from the high- $n$ states $(10<n \leq \infty)$ to total recombination is included as the "top-up" part. This is obtained in the hydrogenic approximation (Nahar 1996). This contribution is important at low temperatures but negligible at high temperatures. At low temperatures, the recombination rate is dominated by the RR into the infinite number of high- $n$ states, as electron energies are not usually high enough for resonant excitations and DR, and causes a rapid rise in $\alpha_{R}(T)$ toward low temperatures.

It might be noted that the present method is unified in principle and not restricted to $n=n_{0}=10$. It can readily be extended to higher $n$ (strictly speaking we refer to the effective quantum number $\nu$ ). However, (1) a detailed calculation of BPRM photoionization cross sections of high- $n$ levels is unnecessary since they approach hydrogenic behavior, and (2) a more accurate DR treatment (Bell \& Seaton 1985; Nahar \& Pradhan 1994) can be employed for $n>10$ when the background (RR) is small and DR dominates the total recombination.

\section{COMPUTATIONS}

Relativistic BPRM calculations in intermediate coupling are carried out in the close-coupling approximation using the $\boldsymbol{R}$-matrix package of codes. These codes are extensions of the Opacity Project codes (Berrington et al. 1987) to include relativistic effects (Scott \& Burke 1980; Scott \& Taylor 1982; Berrington et al. 1995), as implemented under the Iron Project (Hummer et al. 1993). The calculations span several stages of computation using one-electron orbital wave functions for the core or target ion from an updated version of the atomic structure code SUPERSTRUCTURE, using a scaled Thomas-Fermi-Dirac potential (Eissner et al. 1974).

The wave function expansion for $\mathrm{O}$ vi consists of 17 finestructure levels of configurations $1 s^{2}, 1 s 2 s, 1 s 2 p, 1 s 3 s, 1 s 3 p$, and $1 s 3 d$ of $\mathrm{O}$ viI. The levels, along with their relative energies, are given in Table 1. The set of correlation configurations in the atomic structure calculations and the ThomasFermi scaling parameter $\left(\lambda_{\mathrm{nl}}\right)$ for each orbital are also given in Table 1. The second term in equation (3), with bound state correlation functions for $\mathrm{O}$ VI, includes all possible $(N+1)$-particle configurations from 0 to maximum orbital occupancies: $2 s^{2}, 2 p^{2}, 3 s^{2}, 3 p^{2}, 3 d^{2}, 4 s$ and $4 p$.

For $\mathrm{O}$ VII, the wave function expansion consists of 16 fine-structure levels of $\mathrm{O}$ vIII of $1 s, 2 s, 2 p, 3 s, 3 p, 3 d, 4 s, 4 p$, $4 d$, and $4 f$, as given in Table 1 . The bound state correlation functions included all configurations from 0 to maximum

TABLE 1

\begin{tabular}{|c|c|c|c|c|}
\hline \multirow[b]{2}{*}{ KEY } & \multicolumn{2}{|c|}{ O vII } & \multicolumn{2}{|c|}{ O VIII } \\
\hline & Level & $\begin{array}{c}E_{t}^{*} \\
\text { (ryd) }\end{array}$ & Level & $\begin{array}{c}E_{t}^{*} \\
(\mathrm{ryd})\end{array}$ \\
\hline $1 \ldots$ & $1 s^{2}\left({ }^{1} S_{0}\right)$ & 0.0 & $1 s\left({ }^{2} S_{1 / 2}\right)$ & 0.00 \\
\hline $2 .$. & $1 s 2 s\left({ }^{3} S_{1}\right)$ & 41.232 & $2 p\left({ }^{2} P_{1 / 2}^{o}\right)$ & 48.0308997 \\
\hline ................. & $1 s 2 p\left({ }^{3} P_{0}^{o}\right)$ & 41.787 & $2 s\left({ }^{2} S_{1 / 2}\right)$ & 48.0315698 \\
\hline 4 & $1 s 2 p\left({ }^{3} P_{1}^{o}\right)$ & 41.788 & $2 p\left({ }^{2} P_{3 / 2}^{o}\right)$ & 48.0445917 \\
\hline $5 \ldots \ldots \ldots \ldots \ldots \ldots \ldots \ldots \ldots \ldots \ldots \ldots \ldots \ldots \ldots$ & $1 s 2 p\left({ }^{3} P_{2}^{o}\right)$ & 41.793 & $3 p\left({ }^{2} P_{1 / 2}^{o}\right)$ & 56.9304970 \\
\hline 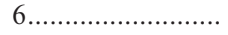 & $1 s 2 s\left({ }^{1} S_{0}\right)$ & 41.812 & $3 s\left({ }^{2} S_{1 / 2}\right)$ & 56.9306973 \\
\hline $7 \ldots \ldots \ldots \ldots \ldots \ldots \ldots$ & $1 s 2 p\left({ }^{1} P_{1}^{o}\right)$ & 42.184 & $3 d\left({ }^{2} D_{1 / 2}\right)$ & 56.9345473 \\
\hline $8 \ldots \ldots$ & $1 s 3 s\left({ }^{3} S_{1}\right)$ & 48.651 & $3 p\left({ }^{2} P_{3 / 2}^{o}\right)$ & 56.9345541 \\
\hline ............... & $1 s 3 p\left({ }^{3} P_{0}\right)$ & 48.804 & $3 d\left({ }^{2} D_{5 / 2}\right)$ & 56.9358976 \\
\hline $10 \ldots \ldots \ldots \ldots \ldots \ldots \ldots \ldots \ldots \ldots \ldots \ldots \ldots$ & $1 s 3 p\left({ }^{3} P_{1}^{o}\right)$ & 48.804 & $4 p\left({ }^{2} P_{1 / 2}^{o}\right)$ & 60.0447993 \\
\hline $11 \ldots \ldots \ldots \ldots \ldots \ldots \ldots \ldots \ldots \ldots \ldots \ldots \ldots$ & $1 s 3 p\left({ }^{3} P_{2}^{o}\right)$ & 48.804 & $4 s\left({ }^{2} S_{1 / 2}\right)$ & 60.0448841 \\
\hline $12 \ldots \ldots \ldots \ldots \ldots \ldots \ldots \ldots \ldots \ldots \ldots \ldots$ & $1 s 3 s\left({ }^{1} S_{0}\right)$ & 48.811 & $4 d\left({ }^{2} D_{3 / 2}\right)$ & 60.0465078 \\
\hline n............. & $1 s 3 d\left({ }^{3} D_{3}\right)$ & 48.884 & $4 p\left({ }^{2} P_{3 / 2}^{o}\right)$ & 60.0465108 \\
\hline ............... & $1 s 3 d\left({ }^{3} D_{2}\right)$ & 48.884 & $4 f\left({ }^{2} P_{5 / 2}^{o}\right)$ & 60.0470765 \\
\hline $15 \ldots \ldots \ldots \ldots \ldots \ldots \ldots \ldots$ & $1 s 3 d\left({ }^{3} D_{1}\right)$ & 48.884 & $4 d\left({ }^{2} D_{5 / 2}\right)$ & 60.0470775 \\
\hline $16 \ldots \ldots \ldots \ldots \ldots \ldots \ldots \ldots \ldots \ldots \ldots \ldots$ & $1 s 3 d\left({ }^{1} D_{1}\right)$ & 48.894 & $4 f\left({ }^{2} P_{7 / 2}^{o}\right)$ & 60.0473612 \\
\hline $17 \ldots \ldots$ & $1 s 3 p\left({ }^{1} P_{1}^{o}\right)$ & 48.922 & & \\
\hline
\end{tabular}

Target LeVels in the Eigenfunction Expansions of O VII AND O VIII (All Energies Are Compiled from the NiST Web-Table)

Notes.-O VII: Correlations- $2 s^{2}, 2 p^{2}, 3 s^{2}, 3 p^{2}, 3 d^{2}, 2 s 2 p, 2 s 3 s$, $2 s 3 p, 2 s 3 d, 2 s 4 s, 2 s 4 p, 2 p 3 s, 2 p 3 p, 2 p 3 d, 2 p 4 s, 2 p 4 p, \lambda_{\mathrm{n}}-0.991(1 s)$, $0.991(2 s), 0.776(2 p), 1.16883(3 s), 0.91077(3 p), 1.00746(3 d),-1.59699(4 s)$, $-1.61237(4 p)$ - see text. O viII: No correlation; $\lambda_{\mathrm{nl}}-1.0$, for $1 s$ to $4 f$. 
orbital occupancies: $1 s^{2}, 2 s^{2}, 2 p^{2}, 3 s^{2}, 3 p^{2}, 3 d^{2}, 4 s^{2}$, and $4 p^{2}$, $4 d$, and $4 f$. The energies in Table 1 are observed values. ${ }^{1}$ Although calculated energies are less than $1 \%$ of the observed ones, the latter are used in the computations to obtain more accurate positions of resonances. Radial integrals for the partial wave expansion in equation (3) are specified for orbitals $0 \leq l \leq 9$, with an $\boldsymbol{R}$-matrix basis set of 40 "continuum" functions (NRANG2) for O VI, and 30 for $\mathrm{O}$ VII.

Both the partial and the total photoionization cross sections are obtained for all bound levels. Coupled channel calculations for $\sigma_{\mathrm{PI}}$ include both the background and the resonance structures (due to the doubly excited autoionizing states) in the cross sections. Radiation damping of resonances up to $n=10$ are included through use of the extended codes STGF and STGBF (Nahar \& Pradhan 1994; Zhang et al. 1999). The BPRM calculations are carried out for each total angular momentum symmetry $J \pi$, corresponding to a set of fine-structure target levels $J_{t}$. Radiation damping of resonances within the close-coupling BPRM calculations are described in Zhang et al. (1999, and references therein). The program PBRRAD is used to extend the total photoionization cross sections in the high-energy region, beyond the highest target threshold in the close-coupling wave function expansion of the ion, by a "tail" using Kramer's formula, $\sigma_{\mathrm{PI}}(E)=\sigma_{\mathrm{PI}}^{o}\left(E^{o} / E\right)^{3}$, where $E^{o}$ is the last tabulated energy and cross section above all target thresholds.

Level-specific recombination cross sections $\sigma_{\mathrm{RC}}(i)$, into bound levels $i \equiv n$ (SLJ) of the recombined ( $e+$ ion) system, are obtained from partial photoionization cross sections $\sigma_{\mathrm{PI}}(i, g)$ of the level $i$ into the ground level $g$ of the recombining ion. These detailed photorecombination cross sections are calculated in the energy region from the threshold energy up to $E\left(\nu=\nu_{o} \approx 10.0\right)$, where $\nu$ is the effective quantum number relative to the target level of the recombining ion. The resonances up to $\nu \leq \nu_{o}$ are delineated with a fine energy mesh. The electrons in this energy range generally recombine to a large number of final $(e+$ ion) levels. Recombination cross sections are computed for all coupled symmetries and levels and summed to obtain the total $\sigma_{\mathrm{RC}}$. Level-specific recombination rate coefficients are obtained using a new computer program, BPRRC (Nahar et al. 2000). The level-specific rate coefficients are obtained for energies going up to infinity. These values include both nonresonant and resonant contributions up to energies $z^{2} / \nu_{o}^{2}$; Contributions from all autoionizing resonances up to $\nu \leq \nu_{o} \approx 10$ are included.

In the higher energy region, $\nu_{o}<\nu<\infty$, below each target threshold where the resonances are narrow and dense and the background is negligible, we compute detailed and resonance averaged DR cross sections. The BPRM DR collision strengths are obtained using extensions of the $\boldsymbol{R}$-matrix asymptotic region code STGF (Nahar \& Pradhan 1994; Zhang et al. 1999). It is necessary to use a very fine energy mesh in order to delineate the resonance structures.

The program BPRRC sums up the level-specific rate coefficients, which is added to the contributions from the resonant high- $n$ DR, from resonances with $\nu_{o}<\nu<\infty$, to obtain total recombination rate coefficients. As an additional check on the numerical calculations, the total recombination rate coefficients, $\alpha_{R}$, are also calculated from the

\footnotetext{
${ }^{1}$ From the NIST Web site: http://www.nist.gov.
}

total recombination collision strength, $\Omega_{\mathrm{RC}}$, obtained from all the photoionization cross sections, and the DR collision strengths. The agreement between the two numerical approaches is within a few percent.

Finally, the small background (nonresonant) contribution from the high- $n$ states $(10<n \leq \infty)$ to total recombination is also included as the "top-up" part, computed in the hydrogenic approximation (Nahar 1996). This contribution is important at low temperatures but negligible at high temperatures. At low temperatures, the recombination rate is dominated by the RR into the infinite number of high- $n$ states, as electron energies are not usually high enough for resonant excitations and DR, and causes a rapid rise in $\alpha_{R}(T)$ toward low temperatures.

Background photoionization cross sections for the high- $n$ group B levels are computed hydrogenically, as explained in Nahar (1996), based on the procedure by Storey \& Hummer (1992) and Hummer (1994).

\section{RESULTS AND DISCUSSION}

Results are presented for photoionization and recombination of $\mathrm{O}$ VII $+e \longleftrightarrow \mathrm{O}$ VI $+h \nu$, and $\mathrm{O}$ VIII $+e \longleftrightarrow$ $\mathrm{O}$ VII $+h \nu$. Odd and even parity energy levels $n$ (SLJ) of total angular momentum symmetries $1 / 2 \leq J \leq 17 / 2$ are considered for $\mathrm{O}$ VI, and $0 \leq J \leq 4$ for $\mathrm{O}$ VII, all bound levels with $n \leq 10$.

Photoionization cross sections $\sigma_{\mathrm{PI}}$ include both the total cross section, leaving the core (residual) ion in the ground and excited levels, as well as the partial cross sections, leaving the core ion in the ground level only. The total cross sections are needed in astrophysical applications, such as in ionization balance calculations, while partial cross sections are needed for applications such as for recombination rate coefficients. (Both the total and the partial cross sections are available electronically from the author.)

Level-specific and total recombination rate coefficients using the BPRM unified treatment, $\alpha_{i}(n \mathrm{SLJ}, n \leq 10)$ and $\alpha_{\mathrm{RC}}(T)$, respectively, are presented for O VI and O VII. In the following subsections we describe salient features pertaining to $\alpha_{\mathrm{RC}}(T)$ in numerical form and in figures. Total $\alpha_{\mathrm{RC}}(T)$ are computed two different ways to enable numerical checks: (1) from the sum of the level-specific rate coefficients and the high- $n$ DR contribution, and (2) from total collision strengths calculated from photoionization cross sections directly, and the DR contribution. The differences between the two are typically within a few percent, thus providing a numerical and self-consistency check particularly on the resolution of resonances.

We also present total recombination rate coefficients for hydrogenic O viII (Nahar 1999) for completeness.

\subsection{O VI}

\subsubsection{Photoionization}

Figures $1 a$ and $1 b$ show the ground state photoionization cross section for $\mathrm{O}$ VI $\left(1 s^{2} 2 s^{2} S_{1 / 2}\right)$. The top panel presents the total photoionization cross section summed over the various target thresholds for ionization, and the bottom panel presents the partial cross sections of the ground level into the ground $1 s^{2}\left({ }^{1} S_{0}\right)$ level of residual ion $\mathrm{O}$ vII. The resonances at high energies belong to the Rydberg series converging on to the $n=2,3$ levels of $\mathrm{O}$ VII $(n=2$ thresholds are marked in Fig. 1). These are the well-known KLL, KLn 


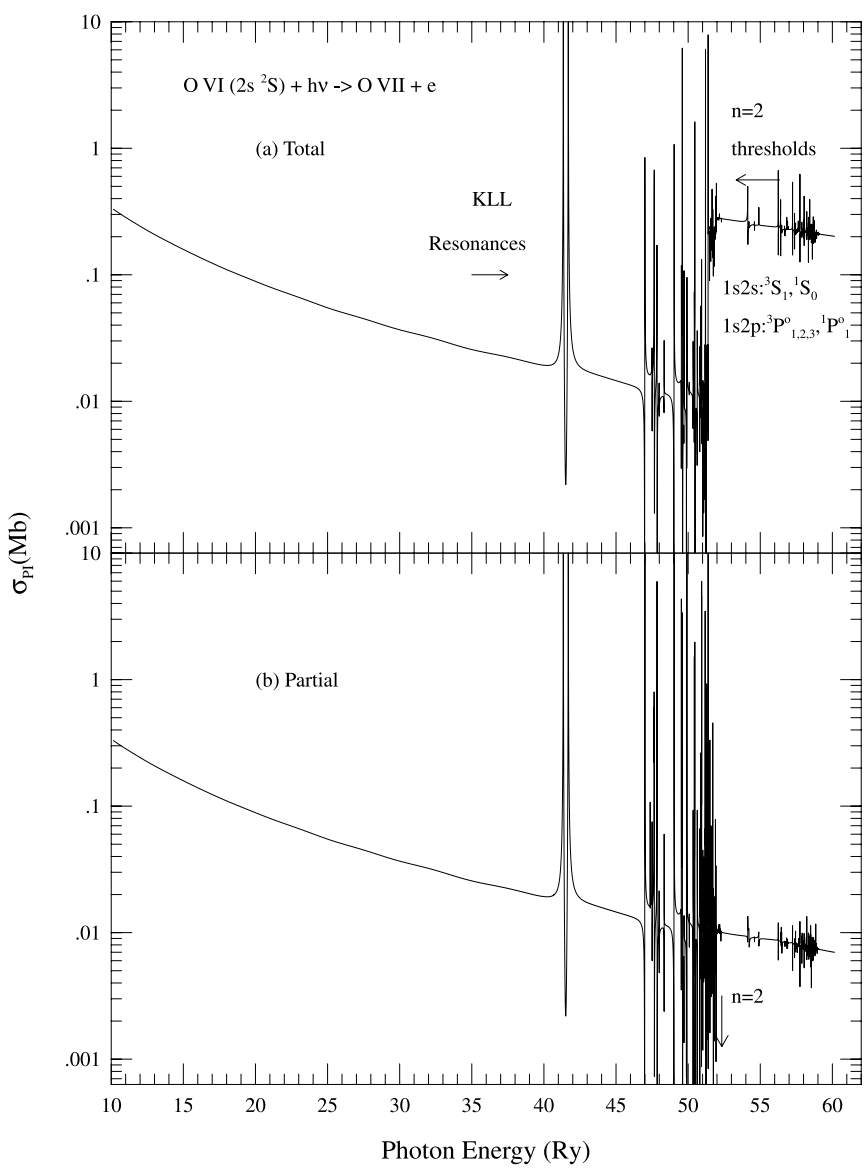

FIG. 1.-Photoionization cross sections of the ground level $1 s^{2} 2 s\left({ }^{2} S_{1 / 2}\right)$ of $\mathrm{O}$ vi: (a) total cross section; the large jump around 52 ryd corresponds to the $n=2 K$-shell ionization edge. (b) Partial cross section into the ground level $1 s^{2}\left({ }^{1} S_{0}\right)$ of $\mathrm{O}$ vII; note that the jump is no longer present and the cross section is continuous across the $n=2$ thresholds of $\mathrm{O}$ VII.

$(n>2)$, as, for example, discussed by Pradhan (2000) and Nahar (1998). Since the first excited levels of $n=2$ thresholds of the core ion $\mathrm{O}$ VII lie at high energies, the cross sections decrease monotonically over a large energy range before the Rydberg series of resonances appears. The total and the partial cross sections are identical below the first excited level of the residual ion beyond which total $\sigma_{\mathrm{PI}}$ increases due to added contributions from excited channels, as shown in the figures. A distinct difference between the total and partial cross sections in Figure 1 comes from the contribution of channels with excited $n=2$ thresholds. The $K$-shell ionization jump at the $n=2$ target levels in total $\sigma_{\mathrm{PI}}$ is due to inner-shell photoionization:

$$
h \nu+\mathrm{O} \text { vI }\left(1 s^{2} 2 s\right) \longrightarrow e+\mathrm{O} \mathrm{vII}(1 s 2 s, 1 s 2 p) .
$$

In X-ray photoionization models inner-shell edges play an important role in overall ionization rates.

Figure 2 presents partial photoionization cross sections of the Rydberg series of levels $1 s^{2} n s, 2 \leq n \leq 10$. As noted in earlier works, photoionization cross section of Rydberg levels exhibit wide resonances known as photoexcitationof-core (PEC) resonances at energies associated with dipole transitions in the core ion. We see such PEC resonances in cross sections of all bound levels of $\mathrm{O}$ vI, as in Figure 2 at photon energies $41.788,42.184,48.804$, and 48.922 ryd due

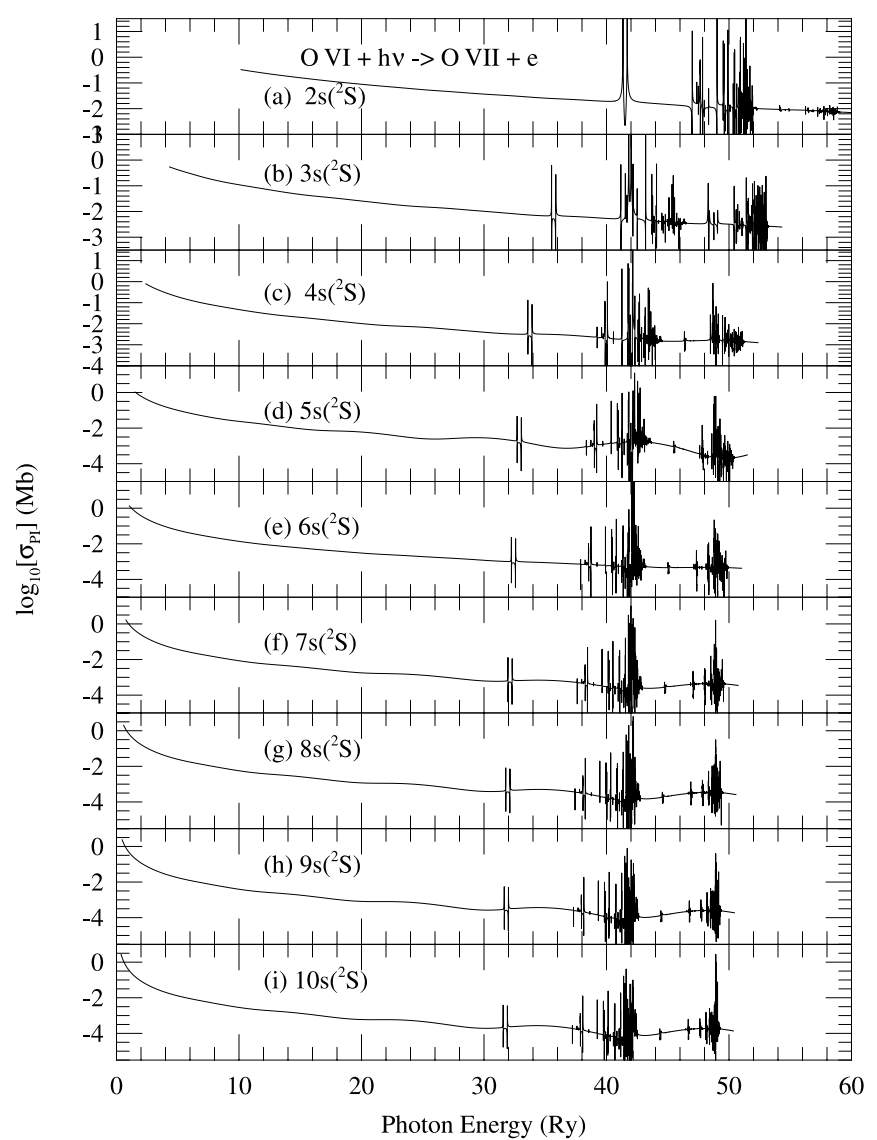

FIG. 2.-Partial photoionization cross sections of the Rydberg series of levels $1 s^{2} n s\left({ }^{2} S_{1 / 2}\right)$ of $\mathrm{O}$ VI into the ground state $1 s^{2}\left({ }^{1} S_{0}\right)$ of $\mathrm{O}$ VII. Photoexcitation-of-core (PEC) resonances are seen at about 42 and 49 ryd.

to core excitations to levels $1 s 2 p\left({ }^{3} P_{1}^{o}\right), 1 s 2 p\left({ }^{1} P_{1}^{o}\right), 1 s 3 p\left({ }^{3} P_{1}^{o}\right)$, and $1 s 3 p\left({ }^{1} P_{1}^{o}\right)$ of $\mathrm{O}$ vII. At these energies the core ion goes through an allowed transition, while the outer electron remains a "spectator" in a doubly excited resonance state, followed by autoionization of the $\mathrm{O}$ VI resonance into the ground level of $\mathrm{O}$ viI. The effect becomes more prominent for cross sections of higher excited levels. For low charge ions, PEC resonances are usually wider. These resonances in $\mathrm{O}$ VI depict the behavior of cross sections that determine corresponding features in level-specific recombination rates.

\subsubsection{Recombination Cross Sections and Rate Coefficients}

The results consist of the total and 98 level-specific $(n \leq 10)$ recombination rate coefficients $\alpha_{R}(T)$ and $\alpha_{i}(T)$ of $\mathrm{O}$ VI, respectively. Total recombination rate coefficients are given in Table 2. These include contributions from all resonances corresponding to the target thresholds up to $n=3$, and corresponding resonance complexes, as given in Table 1 . The main features are illustrated and compared with some of the more recent and accurate data for RR and DR rate coefficients in Figure 3. The solid curve is the BPRM total unified $\alpha_{R}(T)$ and shows typical features. The high values at very low temperature are due to the dominance of RR into an infinity of high- $n$ levels. $\alpha_{R}(T)$ decreases with increasing $T$ until high temperatures where it rises due to the dominance of DR, followed by a monotonous decrease. The dotted curve in Figure 3 is the total rate 
TABLE 2

Total Recombination Rate Coefficients $\alpha_{R}(T)$ FOR O Vi, O VII, AND O VII

\begin{tabular}{|c|c|c|c|c|c|c|c|}
\hline \multirow{2}{*}{\multicolumn{4}{|c|}{$\begin{array}{c}\text { Total Recombination Rate CoefFicients } \alpha_{R}(T) \text { For O vi, } \\
\text { O viI, AND O viII }\end{array}$}} & \multirow{3}{*}{$\begin{array}{l}\log _{10} T \\
(\mathrm{~K})\end{array}$} & \multirow{2}{*}{\multicolumn{3}{|c|}{$\alpha_{R}\left(\mathrm{~cm}^{3} \mathrm{~s}^{-1}\right)$}} \\
\hline & & & & & & & \\
\hline \multirow{3}{*}{$\begin{array}{c}\log _{10} T \\
(\mathrm{~K})\end{array}$} & \multicolumn{3}{|c|}{$\alpha_{R}\left(\mathrm{~cm}^{3} \mathrm{~s}^{-1}\right)$} & & $\mathrm{O}_{\mathrm{VI}}$ & O VII & O VIII \\
\hline & $\mathrm{O}_{\mathrm{VI}}$ & $\mathrm{O}_{\mathrm{VII}}$ & O VIII & $7.2 \ldots \ldots \ldots \ldots \ldots$ & $7.20 \mathrm{E}-13$ & $1.02 \mathrm{E}-12$ & $2.45 \mathrm{E}-13$ \\
\hline & & & & $7.3 \ldots$ & $5.54 \mathrm{E}-13$ & $7.96 \mathrm{E}-13$ & $1.96 \mathrm{E}-13$ \\
\hline $1.0 \ldots \ldots \ldots \ldots \ldots \ldots$ & $1.42 \mathrm{E}-09$ & $1.99 \mathrm{E}-09$ & $2.90 \mathrm{E}-09$ & 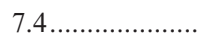 & $4.19 \mathrm{E}-13$ & $6.10 \mathrm{E}-13$ & $1.57 \mathrm{E}-13$ \\
\hline $1.1 \ldots \ldots \ldots \ldots \ldots \ldots$ & $1.25 \mathrm{E}-09$ & $1.76 \mathrm{E}-09$ & $2.56 \mathrm{E}-09$ & $7.5 \ldots \ldots \ldots \ldots \ldots \ldots$ & $3.13 \mathrm{E}-13$ & $4.61 \mathrm{E}-13$ & $1.24 \mathrm{E}-13$ \\
\hline $1.2 \ldots \ldots \ldots \ldots \ldots$ & $1.10 \mathrm{E}-09$ & $1.55 \mathrm{E}-09$ & $2.26 \mathrm{E}-09$ & $7.6 \ldots \ldots \ldots \ldots \ldots \ldots$ & $2.32 \mathrm{E}-13$ & $3.45 \mathrm{E}-13$ & $9.76 \mathrm{E}-14$ \\
\hline $1.3 \ldots \ldots \ldots \ldots \ldots$ & $9.68 \mathrm{E}-10$ & $1.36 \mathrm{E}-09$ & $2.00 \mathrm{E}-09$ & $7.7 \ldots \ldots \ldots$ & $1.70 \mathrm{E}-13$ & $2.56 \mathrm{E}-13$ & $7.63 \mathrm{E}-14$ \\
\hline $1.4 \ldots \ldots \ldots \ldots \ldots \ldots$ & $8.50 \mathrm{E}-10$ & $1.20 \mathrm{E}-09$ & $1.76 \mathrm{E}-09$ & 7.8. & $1.24 \mathrm{E}-13$ & $1.89 \mathrm{E}-13$ & $5.93 \mathrm{E}-14$ \\
\hline $1.5 \ldots \ldots \ldots \ldots \ldots \ldots$ & $7.46 \mathrm{E}-10$ & $1.05 \mathrm{E}-09$ & $1.55 \mathrm{E}-09$ & 7.9. & $9.00 \mathrm{E}-14$ & $1.38 \mathrm{E}-13$ & $4.59 \mathrm{E}-14$ \\
\hline $1.6 \ldots \ldots \ldots \ldots \ldots$ & $6.53 \mathrm{E}-10$ & $9.23 \mathrm{E}-10$ & $1.36 \mathrm{E}-09$ & $8.0 \ldots \ldots \ldots \ldots$ & $6.50 \mathrm{E}-14$ & $1.01 \mathrm{E}-13$ & $3.51 \mathrm{E}-14$ \\
\hline $1.7 \ldots \ldots \ldots \ldots \ldots$ & $5.72 \mathrm{E}-10$ & $8.10 \mathrm{E}-10$ & $1.20 \mathrm{E}-09$ & $8.1 \ldots \ldots \ldots \ldots \ldots$ & $4.69 \mathrm{E}-14$ & $7.35 \mathrm{E}-14$ & $2.70 \mathrm{E}-14$ \\
\hline $1.8 \ldots \ldots \ldots \ldots \ldots \ldots$ & $5.01 \mathrm{E}-10$ & $7.10 \mathrm{E}-10$ & $1.05 \mathrm{E}-09$ & $8.2 \ldots \ldots \ldots \ldots \ldots \ldots$ & $3.37 \mathrm{E}-14$ & $5.33 \mathrm{E}-14$ & $2.05 \mathrm{E}-14$ \\
\hline $1.9 \ldots \ldots \ldots \ldots \ldots$ & $4.38 \mathrm{E}-10$ & $6.21 \mathrm{E}-10$ & $9.26 \mathrm{E}-10$ & $8.3 \ldots \ldots \ldots \ldots \ldots \ldots$ & $2.42 \mathrm{E}-14$ & $3.86 \mathrm{E}-14$ & $1.55 \mathrm{E}-14$ \\
\hline $2.0 \ldots \ldots \ldots \ldots \ldots \ldots$ & $3.83 \mathrm{E}-10$ & $5.44 \mathrm{E}-10$ & $8.12 \mathrm{E}-10$ & 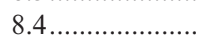 & $1.73 \mathrm{E}-14$ & $2.79 \mathrm{E}-14$ & $1.16 \mathrm{E}-14$ \\
\hline $2.1 \ldots \ldots \ldots \ldots \ldots \ldots$ & $3.34 \mathrm{E}-10$ & $4.75 \mathrm{E}-10$ & $7.12 \mathrm{E}-10$ & 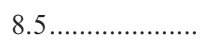 & $1.24 \mathrm{E}-14$ & $2.02 \mathrm{E}-14$ & $8.72 \mathrm{E}-15$ \\
\hline $2.2 \ldots \ldots \ldots \ldots \ldots \ldots$ & $2.91 \mathrm{E}-10$ & $4.15 \mathrm{E}-10$ & $6.23 \mathrm{E}-10$ & 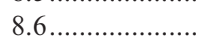 & $8.87 \mathrm{E}-15$ & $1.45 \mathrm{E}-14$ & $6.51 \mathrm{E}-15$ \\
\hline $2.3 \ldots \ldots \ldots \ldots \ldots \ldots$ & $2.54 \mathrm{E}-10$ & $3.62 \mathrm{E}-10$ & $5.46 \mathrm{E}-10$ & $8.7 \ldots$ & $6.33 \mathrm{E}-15$ & $1.05 \mathrm{E}-14$ & $4.83 \mathrm{E}-15$ \\
\hline $2.4 \ldots \ldots \ldots \ldots \ldots \ldots \ldots$ & $2.21 \mathrm{E}-10$ & $3.16 \mathrm{E}-10$ & $4.78 \mathrm{E}-10$ & 8.8 & $4.52 \mathrm{E}-15$ & $7.55 \mathrm{E}-15$ & $3.58 \mathrm{E}-15$ \\
\hline $2.5 \ldots \ldots \ldots \ldots \ldots \ldots \ldots \ldots$ & $1.93 \mathrm{E}-10$ & $2.76 \mathrm{E}-10$ & $4.18 \mathrm{E}-10$ & 8.9 & $3.23 \mathrm{E}-15$ & $5.44 \mathrm{E}-15$ & $2.64 \mathrm{E}-15$ \\
\hline 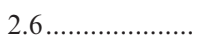 & $1.67 \mathrm{E}-10$ & $2.40 \mathrm{E}-10$ & $3.65 \mathrm{E}-10$ & 9.0 & $2.30 \mathrm{E}-15$ & $3.91 \mathrm{E}-15$ & $1.93 \mathrm{E}-15$ \\
\hline $2.7 \ldots \ldots \ldots \ldots \ldots \ldots$ & $1.46 \mathrm{E}-10$ & $2.09 \mathrm{E}-10$ & $3.19 \mathrm{E}-10$ & & & & \\
\hline
\end{tabular}

TABLE 2-Continued

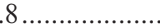

3.0 .

3.1

3.2

3.4

$5 \ldots \ldots \ldots \ldots \ldots$

$3.7 \ldots \ldots \ldots \ldots \ldots \ldots$

3.8

$3.9 \ldots \ldots \ldots \ldots \ldots \ldots$

$4.0 \ldots \ldots \ldots \ldots \ldots \ldots$

4.1 .

$4.2 \ldots \ldots \ldots \ldots \ldots \ldots$

4.3.

$4.4 \ldots \ldots \ldots \ldots \ldots \ldots$

$4.5 \ldots \ldots \ldots \ldots \ldots \ldots$

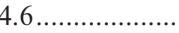

$4.7 \ldots \ldots \ldots \ldots \ldots \ldots$

4.8

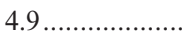

5.0

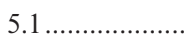

$5.2 \ldots \ldots \ldots \ldots \ldots \ldots$

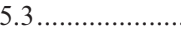

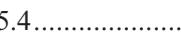

5.5

$5.6 \ldots \ldots \ldots \ldots \ldots \ldots$

5.7

$5.8 \ldots \ldots \ldots \ldots \ldots \ldots$

$5.9 \ldots \ldots \ldots \ldots \ldots \ldots$

6.0

$6.1 \ldots \ldots \ldots \ldots \ldots \ldots$

6.2

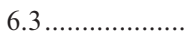

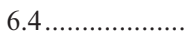

$6.5 \ldots \ldots \ldots \ldots \ldots \ldots$

$6.6 \ldots \ldots \ldots \ldots \ldots \ldots$

$6.7 \ldots$

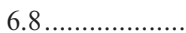

6.9

$7.0 \ldots \ldots \ldots \ldots \ldots \ldots$

7.1

$1.27 \mathrm{E}-10$

$1.10 \mathrm{E}-10$

$9.52 \mathrm{E}-11$

$8.25 \mathrm{E}-11$

$7.15 \mathrm{E}-11$

$6.19 \mathrm{E}-11$

$5.35 \mathrm{E}-11$

$4.62 \mathrm{E}-11$

$3.99 \mathrm{E}-11$

$3.43 \mathrm{E}-11$

$2.96 \mathrm{E}-11$

$2.54 \mathrm{E}-11$

$2.18 \mathrm{E}-11$

$1.87 \mathrm{E}-11$

$1.61 \mathrm{E}-11$

$1.37 \mathrm{E}-11$

$1.17 \mathrm{E}-11$

$1.00 \mathrm{E}-11$

$8.54 \mathrm{E}-12$

$7.26 \mathrm{E}-12$

$6.16 \mathrm{E}-12$

$5.22 \mathrm{E}-12$

$4.41 \mathrm{E}-12$

$3.72 \mathrm{E}-12$

$3.13 \mathrm{E}-12$

$2.62 \mathrm{E}-12$

$2.19 \mathrm{E}-12$

$1.83 \mathrm{E}-12$

$1.52 \mathrm{E}-12$

$1.26 \mathrm{E}-12$

$1.05 \mathrm{E}-12$

8.99E-13

$8.42 \mathrm{E}-13$

$9.14 \mathrm{E}-13$

$1.11 \mathrm{E}-12$

$1.39 \mathrm{E}-12$

$1.65 \mathrm{E}-12$

$1.82 \mathrm{E}-12$

$1.86 \mathrm{E}-12$

$1.78 \mathrm{E}-12$

$1.60 \mathrm{E}-12$

$1.38 \mathrm{E}-12$

$1.14 \mathrm{E}-12$

9.19E-13
$1.82 \mathrm{E}-10$

$1.58 \mathrm{E}-10$

$1.37 \mathrm{E}-10$

$1.19 \mathrm{E}-10$

$1.03 \mathrm{E}-10$

8.97E-11

$7.77 \mathrm{E}-11$

$6.73 \mathrm{E}-11$

$5.82 \mathrm{E}-11$

$5.04 \mathrm{E}-11$

$4.35 \mathrm{E}-11$

$3.76 \mathrm{E}-11$

$3.25 \mathrm{E}-11$

$2.80 \mathrm{E}-11$

$2.41 \mathrm{E}-11$

$2.08 \mathrm{E}-11$

$1.79 \mathrm{E}-11$

$1.54 \mathrm{E}-11$

$1.32 \mathrm{E}-11$

$1.14 \mathrm{E}-11$

$9.77 \mathrm{E}-12$

$8.38 \mathrm{E}-12$

$7.20 \mathrm{E}-12$

$6.16 \mathrm{E}-12$

$5.28 \mathrm{E}-12$

$4.51 \mathrm{E}-12$

$3.85 \mathrm{E}-12$

$3.28 \mathrm{E}-12$

2.79E-12

$2.37 \mathrm{E}-12$

$2.01 \mathrm{E}-12$

$1.72 \mathrm{E}-12$

$1.52 \mathrm{E}-12$

$1.44 \mathrm{E}-12$

$1.52 \mathrm{E}-12$

$1.73 \mathrm{E}-12$

$1.99 \mathrm{E}-12$

$2.21 \mathrm{E}-12$

$2.31 \mathrm{E}-12$

$2.26 \mathrm{E}-12$

$2.10 \mathrm{E}-12$

$1.85 \mathrm{E}-12$

$1.56 \mathrm{E}-12$

$1.28 \mathrm{E}-12$
$2.78 \mathrm{E}-10$

$2.43 \mathrm{E}-10$

$2.12 \mathrm{E}-10$

$1.85 \mathrm{E}-10$

$1.61 \mathrm{E}-10$

$1.40 \mathrm{E}-10$

$1.22 \mathrm{E}-10$

$1.06 \mathrm{E}-10$

$9.22 \mathrm{E}-11$

8.01E-11

$6.95 \mathrm{E}-11$

$6.03 \mathrm{E}-11$

$5.22 \mathrm{E}-11$

$4.53 \mathrm{E}-11$

3.92E-11

3.39E-11

$2.93 \mathrm{E}-11$

$2.53 \mathrm{E}-11$

$2.18 \mathrm{E}-11$

$1.88 \mathrm{E}-11$

$1.62 \mathrm{E}-11$

1.39E-11

$1.19 \mathrm{E}-11$

$1.03 \mathrm{E}-11$

$8.78 \mathrm{E}-12$

$7.51 \mathrm{E}-12$

$6.42 \mathrm{E}-12$

$5.48 \mathrm{E}-12$

4.67E-12

$3.97 \mathrm{E}-12$

$3.37 \mathrm{E}-12$

$2.85 \mathrm{E}-12$

$2.40 \mathrm{E}-12$

$2.03 \mathrm{E}-12$

$1.71 \mathrm{E}-12$

$1.43 \mathrm{E}-12$

$1.20 \mathrm{E}-12$

$9.96 \mathrm{E}-13$

$8.27 \mathrm{E}-13$

$6.84 \mathrm{E}-13$

$5.63 \mathrm{E}-13$

$4.61 \mathrm{E}-13$

$3.75 \mathrm{E}-13$

$3.05 \mathrm{E}-13$ coefficient in $L S$ coupling (Nahar 1999). The difference between the $L S$ coupling $\alpha_{R}(T)$ and the present BPRM rate coefficient is due to relativistic effects and radiation damping of low- $n$ resonances. Both effects can be important for

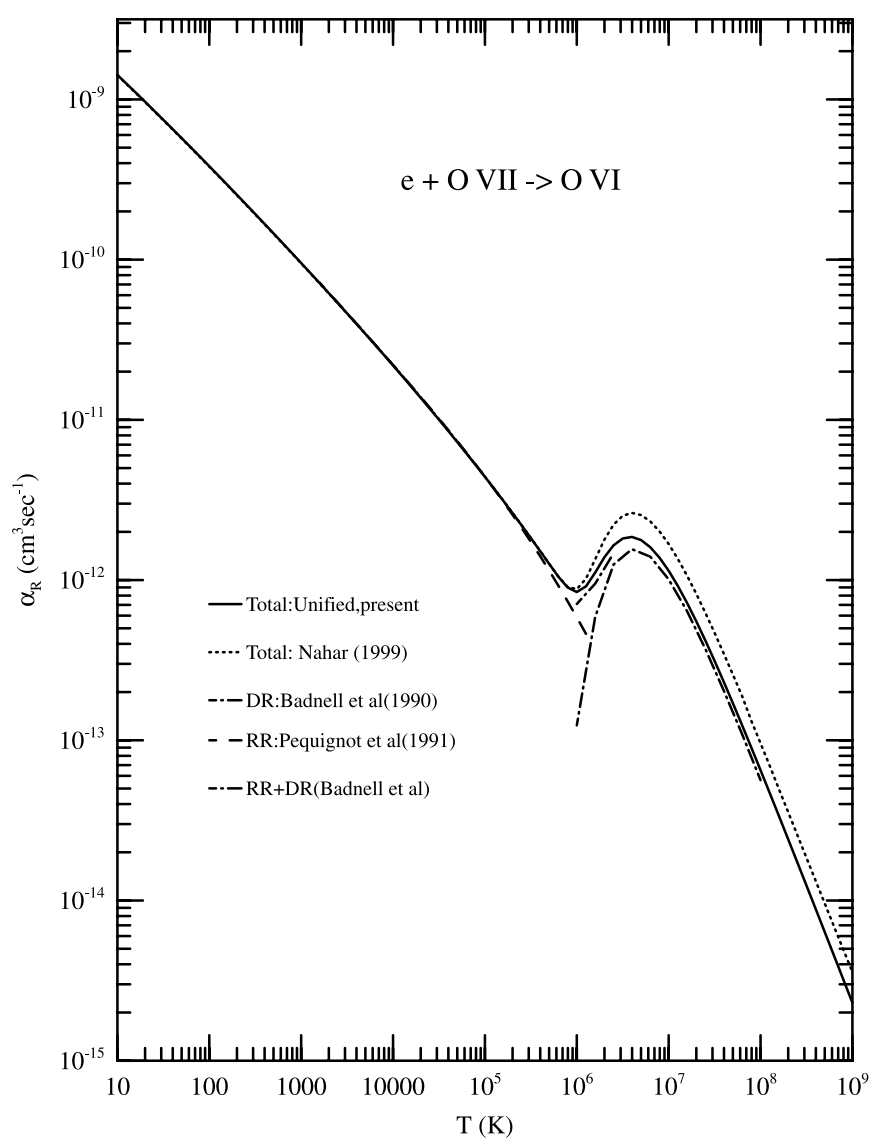

FIG. 3.-Total unified recombination rate coefficients for O vI: BPRM with fine structure (solid curve); total in LS coupling (Nahar 1999; dotted curve): RR rates by Pequignot et al. (1991; dashed curve), DR rates by Badnell et al. (1990; dot-dashed curve). 
highly charged ions. The dashed curve is the $\mathrm{RR}$ rate coefficient by Pequignot et al. (1991), partially obtained by smoothing some of the OP data over resonances, and hydrogenic approximation. The agreement is good in the low region since nonresonant cross sections dominate the lowenergy region. The dot-dashed curve is the DR rate coefficient by Badnell et al. (1990) using the isolated resonance approximation; their results are shown in the crucial temperature range of interest, but they also extend toward higher temperatures and are in agreement with ours. The sum of previous RR and DR rate coefficients agrees with the present unified rate coefficients to about $10 \%-20 \%$, as expected for highly charged ions.

The 98 level-specific recombination rate coefficients $\alpha_{i}(T)$ for $\mathrm{O}$ vi are for $i \equiv n(\mathrm{SLJ}), n \leq 10$ and $l \leq 9$, and associated $J \pi$ levels. Figure 4 presents $\alpha_{i}(T)$ into eight $n=2$ and 3 levels with $n$ (SLJ): $2 s^{2} S_{0}, 2 p{ }^{2} P_{1 / 2,3 / 2}^{o}, 3 s^{2} S_{0}, 3 p^{2} P_{1 / 2,3 / 2}^{o}$, and $3 d^{2} D_{3 / 2,5 / 2}$. These rate coefficients are relatively smooth except for a small and diffuse DR "bump." The levels correspond to the prominent 1032 and $1038 \AA$ UV doublet lines, respectively, in $\mathrm{O}$ vi spectra arising because of strong dipole transitions ${ }^{2} P_{3 / 2,1 / 2}^{o} \longrightarrow{ }^{2} S_{1 / 2}$.

Total photorecombination cross sections $\sigma_{\mathrm{RC}}$ show features similar to photoionization cross sections $\sigma_{\mathrm{PI}}$-smooth decay with energy, before the resonance complexes begin to emerge at high energies. However, $\sigma_{\mathrm{RC}}$ are more complicated than $\sigma_{\mathrm{PI}}$ since all levels contribute to the total $\sigma_{\mathrm{RC}}$,

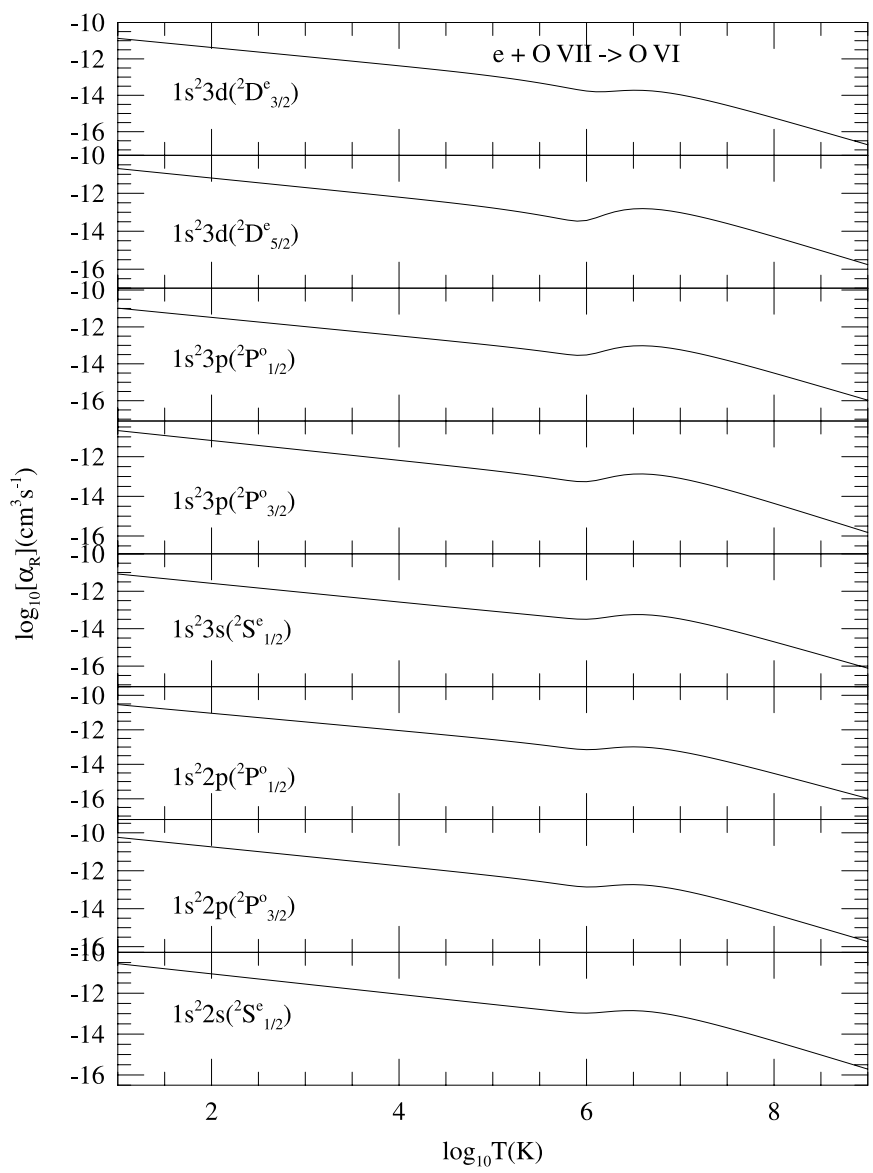

FIG. 4.-Level-specific recombination rate coefficients for $\mathrm{O}$ VI recombining to ground and excited $n=2,3$ levels. The strong dipole transitions ${ }^{2} P_{3,21 / 2}^{o} \longrightarrow{ }^{2} S_{1 / 2}$ are responsible for the prominent 1032 and $1038 \AA$ $\mathrm{UV}$ doublet lines, respectively, in $\mathrm{O}$ vi spectra.

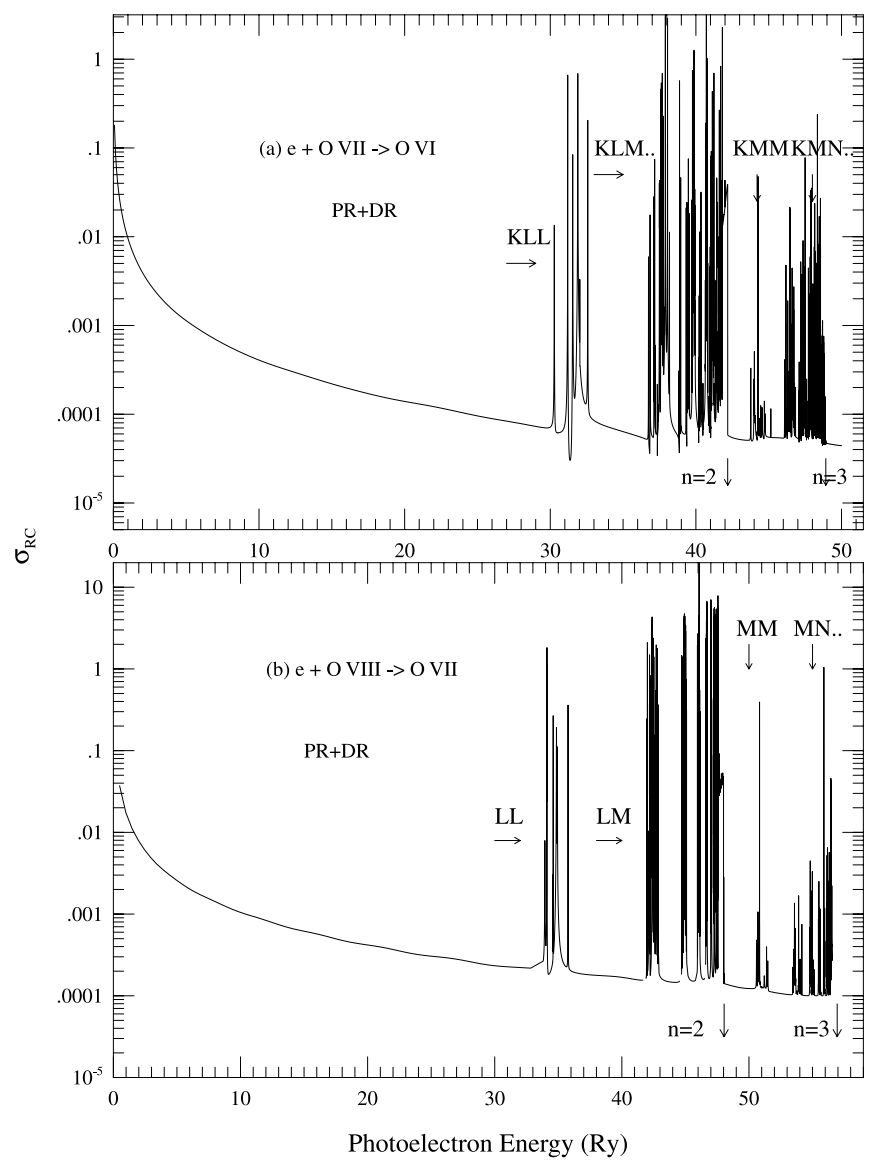

FIG. 5.-Total unified $\left(e+\right.$ ion) photorecombination cross sections, $\sigma_{\mathrm{RC}}$, of (a) $\mathrm{O}$ VI and (b) $\mathrm{O}$ VII. Note that the $\sigma_{\mathrm{RC}}$ exhibit considerably more resonance structures than the corresponding ground level $\sigma_{\mathrm{PI}}$ in Figs. 1 and 6 , since the former are summed over the ground and many excited recombined levels.

shown in Figure $5 a$ for $\mathrm{O}$ vi. The resonance complexes are marked as KLL, KLM, KLN, etc. For heavier high- $Z$ elements than oxygen $(Z>10)$ these manifest themselves as dielectronic satellite lines observed in tokamaks, electronbeam-ion-traps (EBIT), ion storage rings, and astrophysical sources. The KLL complexes have been well studied in previous works (e.g., Gabriel 1972; Bely-Dubau et al. 1982; Pradhan \& Zhang 1997b; Zhang et al. 1999; Beiersdorfer et al. 1992; Oelgoetz \& Pradhan 2001) for various ions.

\subsection{O VII}

\subsubsection{Photoionization}

Total and partial photoionization cross sections $\sigma_{\mathrm{PI}}$ for 116 levels $n$ (SLJ) $(n \leq 10)$ are presented for O VII (the partial cross sections are for ionization into the ground level $1 \mathrm{~s}$ ${ }^{2} S_{1 / 2}$ of $\mathrm{O}$ vIII). Illustrative results are presented in Figure 6. Figure $6 a$ shows the photoionization cross section of the ground level $\left(1 s^{2}{ }^{1} S_{0}\right)$ of O viI. Similar to O vI, the Rydberg series of resonances, KL and $\mathrm{K} n(n>2)$, begins at fairly high energies owing to the high $n=2$ excitation thresholds of $\mathrm{O}$ VIII. However, the ground level $\sigma_{\mathrm{PI}}$ of $\mathrm{O}$ VII does not show a significant $K$-shell jump at the $n=2$ threshold, as seen in $\mathrm{O}$ vi. Nonetheless, the feature is prominent in the excited $n=2$ level cross sections as seen in Figures $6 b-6 e$. These excited levels are responsible for the formation of the important X-ray diagnostic lines, $w, x, y, z$, from the 


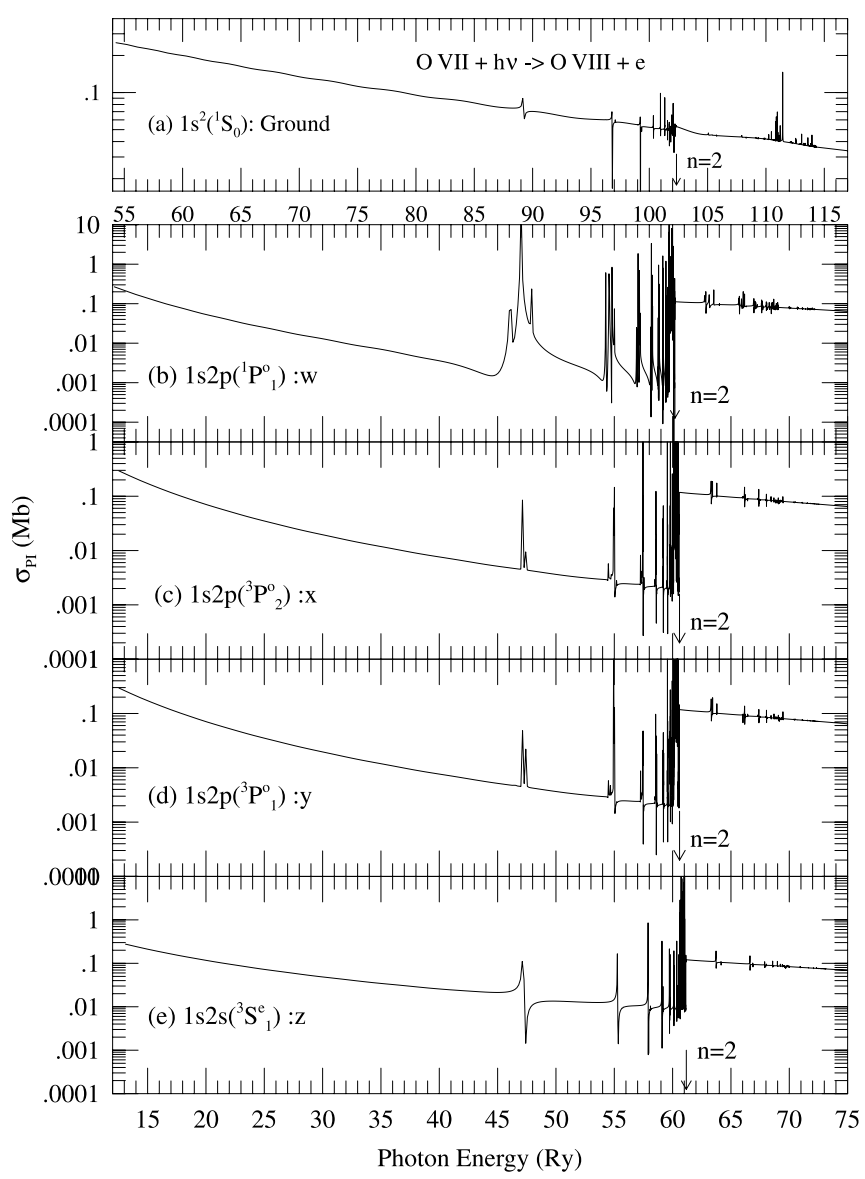

FIG. 6.-Level-specific photoionization cross sections of $(a)$ the ground level $1 s^{2}\left({ }^{1} S_{0}\right)$, and $(b)-(e)$ excited $1 s 2 s$ and $1 s 2 p$ levels of $\mathrm{O}$ vII responsible for the prominent X-ray lines: resonance $(w)$, intercombination $(x, y)$, and forbidden $(z)$

allowed and forbidden transitions

$$
1 s^{2}\left({ }^{1} S_{0}\right) \longleftarrow 1 s 2 p\left({ }^{1} P_{1}^{o}\right), 1 s 2 p\left({ }^{3} P_{2}^{o}\right), 1 s 2 p\left({ }^{3} P_{1}^{o}\right), 1 s 2 s\left({ }^{3} S_{1}\right),
$$

respectively. The $K$-shell ionization jump at the $n=2$ target levels,

$$
h \nu+\mathrm{O} \operatorname{VII}(1 s 2 s, 1 s 2 p) \longrightarrow e+\mathrm{O} \operatorname{VIII}(2 s, 2 p),
$$

can be seen clearly in the photoionization cross sections.

\subsubsection{Recombination Cross Sections and Rate Coefficients}

Total recombination rate coefficients for $\mathrm{O}$ VII over a wide temperature range are presented in Table 2. In Figure 7 the solid curve is the present total recombination rate coefficients, including relativistic effects in BPRM approximation and radiation damping of low- $n(n \leq 10)$ resonances. The solid curve has the same general shape typical of unified recombination rate coefficients - the high values at low temperatures decrease until the recombination is dominated by DR forming a hump at high temperature. The dotted curve in the figure is the earlier total unified rate coefficient (Nahar 1999), where a part of the values, the resonances $2 \operatorname{lnl}$ converging on to the $n=2$ thresholds of $\mathrm{O}$ VIII, were also computed using the BPRM method including radiation damping (Zhang et al. 1999); the remainder was in $L S$ coupling. Both results show very close agreement since the main $n=2$ resonant contributions are the same. However,

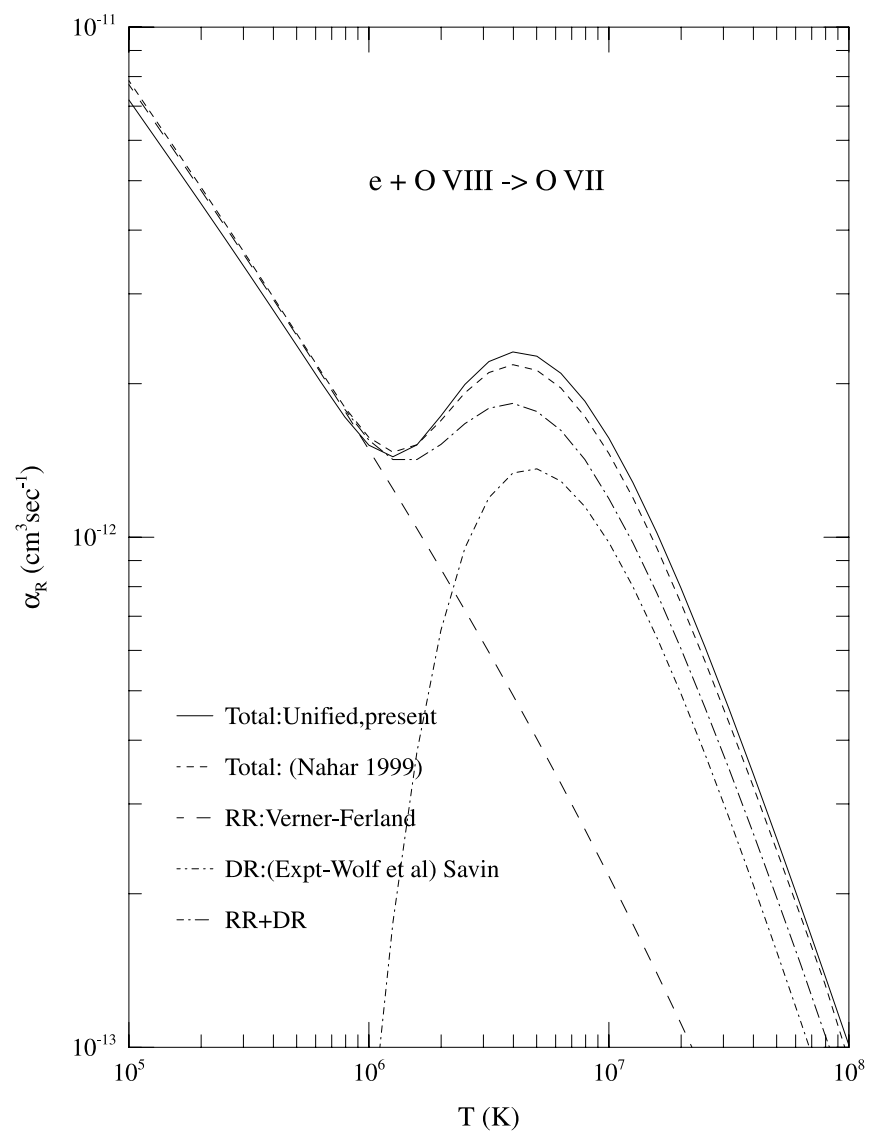

FIG. 7.-Total unified recombination rate coefficients for $\mathrm{O}$ vII: present BPRM (solid curve); total (Nahar 1999; dotted curve), RR rates by Verner \& Ferland (1996; dashed curve), DR rates by Savin (1999) from measured cross sections by Wolf et al. (1991) (dot-dashed curve).

present rate coefficients also include $n=3,4$ resonant contributions $3 \ln l^{\prime}, 4 \ln l^{\prime}$. The dashed curve is the $\mathrm{RR}$ rate coefficient obtained by Verner \& Ferland (1996), which agrees well with the present one in the region where DR is small. The dot-dashed curve is the DR rate coefficient calculated by Savin (1999) from experimentally measured recombination cross sections by Wolf et al. (1991). As is discernible from Figure 7, the sum of the previous RR and the experimental $\mathrm{DR}$ rate coefficient $(\mathrm{RR}+\mathrm{DR})$ (longdashed and dotted curves) is significantly lower than the present unified rate coefficient for $\mathrm{O}$ VII. At the temperature of peak DR contribution $\log T=6.6$, the unified rate coefficient is about $20 \%$ higher the $\mathrm{RR}+\mathrm{DR}$ value. This is most likely because the experimental DR measurements cover a smaller energy range and do not include all contributions. The difference between the previous results up to $2 \ln l^{\prime}$, and the present ones is indicative of the higher $n>2$ contributions as well as other uncertainties.

Level-specific recombination rate coefficients are obtained for $116 n$ (SLJ) levels of O VII with $0 \leq J \leq 4$ and $n \leq 10$. These vales for fine-structure levels were not obtained in our earlier work (Nahar 1999). Figure 8 presents level-specific rate coefficients for the $n=2$ levels corresponding to the $\mathrm{X}$-ray $w, x, y$, and $z$ lines of $\mathrm{O}$ VII. The rate coefficients show a relatively smooth decay with temperature except for the high-temperature DR bump for $1 s 2 p\left({ }^{1} P_{1}^{o}\right)$ and $1 s 2 s\left({ }^{3} S_{1}\right)$ levels. 


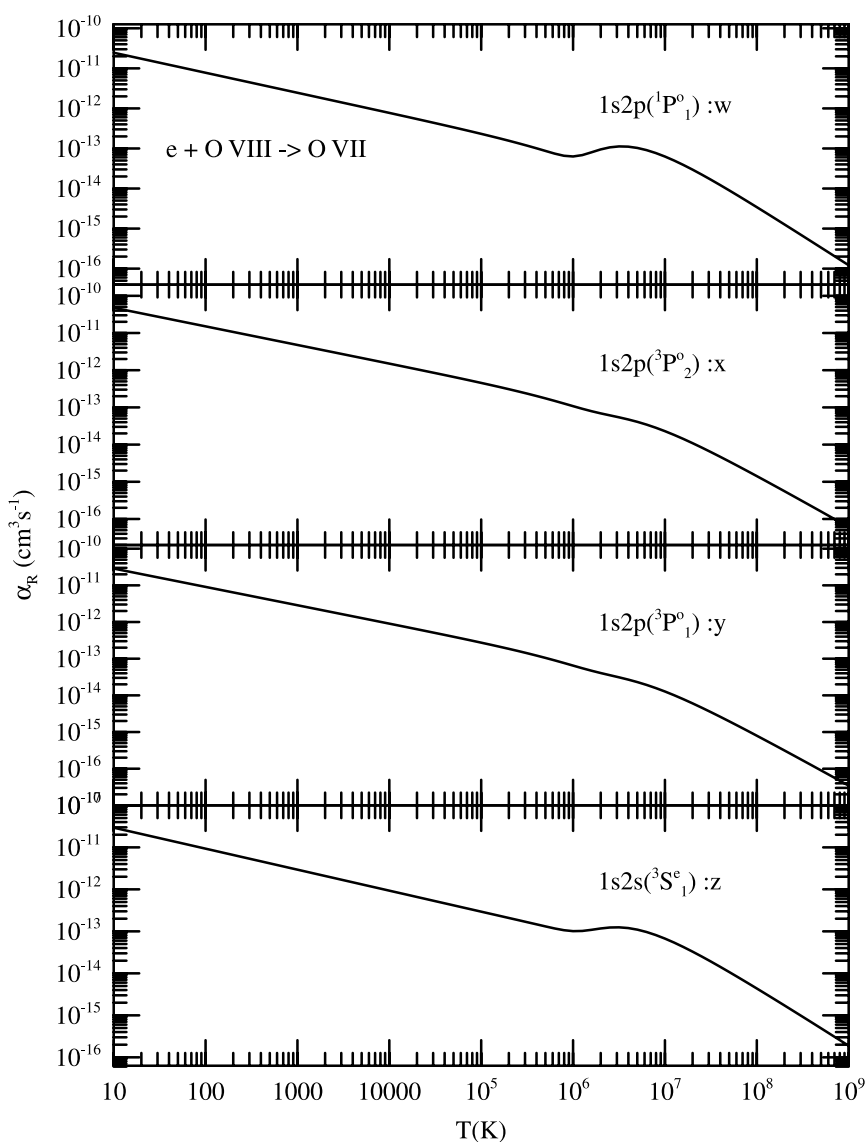

FIG. 8.-Level-specific recombination rate coefficients for $\mathrm{O}$ VII into the excited $n=2$ levels responsible for the prominent X-ray lines $w, x, y$, and $z$.

The total recombination cross sections $\sigma_{\mathrm{RC}}$, summed over recombination cross sections of individual fine-structure levels up to $n=10$ of $\mathrm{O}$ vII and high- $n$ contributions are presented in Figure $5 b$. The resonance complexes LL, LM, LN, MM, etc., of $n=2$ and 3 thresholds of the core are specified in the figure. The $n=4$ resonances are too low for any significant contributions. These complexes are seen at high energies near the high-lying $\mathrm{O}$ viII thresholds.

As mentioned above, as a numerical check on the calculations we verify that the sum of the level-specific rate coefficients and the DR contribution agrees within a few percent with the total recombination rate coefficient obtained from total collision strengths obtained from $\sigma_{\mathrm{RC}}$ in Figure 5 for both $\mathrm{O}$ vi and $\mathrm{O}$ vII.

\subsubsection{Ionization Fractions in Coronal Equilibrium}

Using the present total unified recombination rate coefficients, $\alpha_{R}(T)$, for $\mathrm{O}$ VI and $\mathrm{O}$ vII, and collisional ionization rate coefficients from Bell et al. (1983; see also Nahar 1999), we calculate ionization fractions of oxygen ions in coronal (collisional) equilibrium,

$N(z-1, g) S(z-1, g)=N(z, g) \alpha(z, g), 1 \leq z \leq z_{\max }$,

where $S$ is the rate coefficient for electron impact ionization and total element density $N_{T}=\sum_{z=0}^{z_{\max }} N(z, g)$. The ionization fractions in $-\log \left[N(z) / N_{T}\right]$ are given in Table 3. However, present fractions show very little difference from earlier values (Nahar 1999). Most of the differences are in the third significant digit and do not show up in Table 3.

\section{CONCLUSION}

Extensive results from relativistic calculations for total and level-specific photoionization and recombination cross sections and rate coefficients are presented for $\mathrm{O}$ VI and $\mathrm{O}$ VII. These are of general interest in UV and X-ray spectroscopy of laboratory and astrophysical sources, especially the formation due to recombination of important lines such as the $\lambda \lambda 1032,1038$ fine-structure doublet in $\mathrm{O}$ vi and the " triplet" X-ray features in O viI.

A discussion of some of the important atomic effects such as resolution and radiation damping of resonances, interference between nonresonant (RR) and resonant (DR) recombination, comparison with experimental data and uncertainties, and general features of the unified $(e+$ ion $)$ recombination rate coefficients, has also been given in the first paper on the new BPRM calculations-(Nahar et al. 2000, hereafter Paper IV). Experimental and theoretical results on interference effects between $\mathrm{RR}$ and $\mathrm{DR}$ for $(e+\mathrm{C}$ IV) recombination has been discussed by Pradhan et al. 2001), and for $\left(e+\mathrm{Sc}^{3+}\right)$ recombination by Schippers et al. (1999). Generally, for highly charged ions such effects are small.

Dielectronic satellite rate coefficients for the KLL, KLM, etc., complexes of several ions have been shown earlier to be in very good agreement with experiments and other theoretical calculations (Pradhan \& Zhang 1997a; Zhang et al. 1999 ), to about $10 \%-20 \%$; it is therefore expected that the present rates should be definitive, with similar uncertainties.

The present level-specific data can be used to construct recombination-cascade matrices for $\mathrm{O}$ VI and $\mathrm{O}$ VII, to obtain effective recombination rates into specific finestructure levels $n$ (SLJ) with $n \leq 10$ and $l \leq n-1$ (e.g., Pradhan 1985). The present data are more than sufficient for extrapolation to high- $n, l$ necessary to account for all cascade contributions.

The available data include (A) photoionization cross sections, both total and partial, for bound fine-structure levels of $\mathrm{O}$ vi and $\mathrm{O}$ viI up to the $n=10$ levels, and (B) total unified recombination rate coefficients for $\mathrm{O}$ VI and $\mathrm{O}$ VII, and level-specific recombination rate coefficients for levels up to $n=10$. Further calculations for other He-like and $\mathrm{Li}$-like ions are in progress. All photoionization and recombination data are available electronically from the author (S. N. N.). The total recombination rate coefficients are also available from the Ohio State Atomic Astrophysics Web site. $^{2}$

This work was supported partially by NSF and NASA. The computational work was carried out on the Cray SV1 at the Ohio Supercomputer Center in Columbus, Ohio.

\footnotetext{
${ }^{2}$ See http://www.astronomy.ohio-state.edu/ pradhan.
} 
TABLE 3

Ionization Fractions, $-\operatorname{LOG}_{10}\left[N(z) / N_{T}\right]$, OF OXygen Ions in Coronal Equilibrium

\begin{tabular}{|c|c|c|c|c|c|c|c|c|c|}
\hline \multirow[b]{2}{*}{$\log _{10} T$} & \multicolumn{9}{|c|}{$-\log _{10} N(z) / N_{T}$} \\
\hline & $\mathrm{O}_{\mathrm{I}}$ & O II & O III & O Iv & $\mathrm{Ov}$ & $\mathrm{O}_{\mathrm{VI}}$ & O VII & O vIII & O IX \\
\hline $4.0 \ldots \ldots \ldots \ldots \ldots \ldots .$. & 0.001 & 2.5 & $\ldots$ & $\ldots$ & $\ldots$ & $\ldots$ & $\ldots$ & $\ldots$ & $\ldots$ \\
\hline $4.1 \ldots \ldots \ldots \ldots \ldots \ldots .$. & 0.0433 & 1.02 & $\ldots$ & $\ldots$ & $\ldots$ & $\ldots$ & $\ldots$ & $\ldots$ & $\ldots$ \\
\hline $4.2 \ldots \ldots \ldots \ldots \ldots \ldots$ & 0.432 & 0.2 & 7.91 & $\ldots$ & $\ldots$ & $\ldots$ & $\ldots$ & $\ldots$ & $\ldots$ \\
\hline 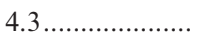 & 1.19 & 0.029 & 5.37 & $\ldots$ & $\ldots$ & $\ldots$ & $\ldots$ & $\ldots$ & $\ldots$ \\
\hline 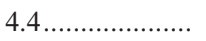 & 1.77 & 0.008 & 3.49 & $\ldots$ & $\ldots$ & $\ldots$ & $\ldots$ & $\ldots$ & $\ldots$ \\
\hline $4.5 \ldots \ldots \ldots \ldots \ldots \ldots \ldots$ & 2.12 & 0.007 & 2.10 & 8.15 & $\ldots$ & $\ldots$ & $\ldots$ & $\ldots$ & $\ldots$ \\
\hline $4.6 \ldots$ & 2.38 & 0.037 & 1.11 & 5.38 & $\ldots$ & $\ldots$ & $\ldots$ & $\ldots$ & $\ldots$ \\
\hline 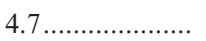 & 2.72 & 0.176 & 0.481 & 3.39 & 9.73 & $\ldots$ & $\ldots$ & $\ldots$ & $\ldots$ \\
\hline 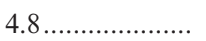 & 3.21 & 0.483 & 0.179 & 2.05 & 6.89 & $\ldots$ & $\ldots$ & $\ldots$ & $\ldots$ \\
\hline $4.9 \ldots \ldots \ldots \ldots \ldots \ldots \ldots$ & 3.82 & 0.901 & 0.096 & 1.14 & 4.76 & $\ldots$ & $\ldots$ & $\ldots$ & $\ldots$ \\
\hline 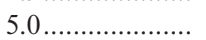 & 4.52 & 1.40 & 0.174 & 0.539 & 3.17 & 7.54 & $\ldots$ & $\ldots$ & $\ldots$ \\
\hline 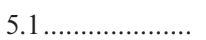 & 5.33 & 2.01 & 0.417 & 0.23 & 2.02 & 5.13 & 8.58 & $\ldots$ & $\ldots$ \\
\hline 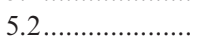 & 6.22 & 2.71 & 0.778 & 0.114 & 1.21 & 3.28 & 5.48 & $\ldots$ & $\ldots$ \\
\hline $5.3 \ldots \ldots \ldots \ldots-1$. & 7.16 & 3.45 & 1.22 & 0.155 & 0.646 & 1.87 & 3.04 & $\cdots$ & $\begin{array}{l}\cdots \\
\cdots\end{array}$ \\
\hline $5.4 \ldots \ldots \ldots \ldots \ldots \ldots \ldots$ & 8.23 & 4.32 & 1.82 & 0.41 & 0.387 & 0.895 & 1.23 & $\ldots$ & $\ldots$ \\
\hline 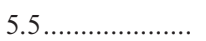 & 9.78 & 5.67 & 2.92 & 1.20 & 0.724 & 0.634 & 0.289 & $\ldots$ & $\ldots$ \\
\hline 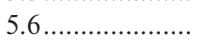 & $\ldots$ & 7.43 & 4.43 & 2.43 & 1.57 & 0.975 & 0.064 & 8.40 & $\ldots$ \\
\hline 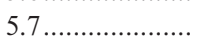 & $\ldots$ & 9.11 & 5.89 & 3.64 & 2.43 & 1.40 & 0.019 & 6.32 & $\ldots$ \\
\hline $5.8 \ldots \ldots \ldots \ldots \ldots \ldots \ldots$. & $\ldots$ & $\ldots$ & 7.19 & 4.71 & 3.18 & 1.78 & 0.007 & 4.66 &. \\
\hline 5.9 & $\ldots$ & $\ldots$ & 8.33 & 5.63 & 3.82 & 2.10 & 0.004 & 3.31 & 7.86 \\
\hline & $\ldots$ & $\ldots$ & 9.31 & 6.41 & 4.34 & 2.34 & 0.005 & 2.23 & 5.52 \\
\hline 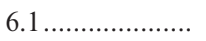 & $\ldots$ & $\ldots$ & $\ldots$ & 7.05 & 4.75 & 2.49 & 0.020 & 1.39 & 3.66 \\
\hline 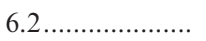 & $\ldots$ & $\ldots$ & $\ldots$ & 7.61 & 5.09 & 2.60 & 0.080 & 0.795 & 2.24 \\
\hline 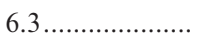 & $\ldots$ & $\ldots$ & $\ldots$ & 8.19 & 5.47 & 2.76 & 0.231 & 0.455 & 1.22 \\
\hline 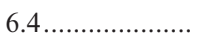 & $\ldots$ & $\ldots$ & $\ldots$ & 8.89 & 5.98 & 3.08 & 0.527 & 0.368 & 0.56 \\
\hline 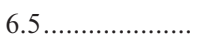 & $\ldots$ & $\ldots$ & $\ldots$ & 9.74 & 6.65 & 3.56 & 0.984 & 0.51 & 0.231 \\
\hline 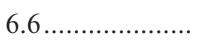 & $\ldots$ & $\ldots$ & $\ldots$ & $\ldots$ & 7.41 & 4.15 & 1.52 & 0.77 & 0.096 \\
\hline 6.7 …................ & $\ldots$ & $\ldots$ & $\ldots$ & $\ldots$ & 8.16 & 4.75 & 2.05 & 1.06 & 0.044 \\
\hline 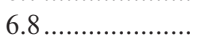 & $\ldots$ & $\ldots$ & $\ldots$ & $\ldots$ & 8.90 & 5.33 & 2.55 & 1.33 & 0.022 \\
\hline 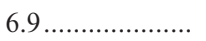 & $\ldots$ & $\ldots$ & $\ldots$ & $\ldots$ & 9.59 & 5.88 & 3.00 & 1.57 & 0.012 \\
\hline 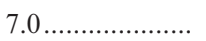 & $\ldots$ & $\ldots$ & $\ldots$ & $\ldots$ & $\ldots$ & 6.41 & 3.42 & 1.79 & 0.007 \\
\hline 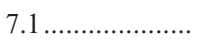 & $\ldots$ & $\ldots$ & $\ldots$ & $\ldots$ & $\ldots$ & 6.91 & 3.81 & 1.98 & 0.005 \\
\hline 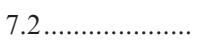 & $\ldots$ & $\ldots$ & $\ldots$ & $\ldots$ & $\ldots$ & 7.39 & 4.17 & 2.16 & 0.003 \\
\hline 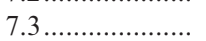 & $\ldots$ & $\ldots$ & $\ldots$ & $\ldots$ & $\ldots$ & 7.85 & 4.50 & 2.32 & 0.002 \\
\hline 7.4 & $\ldots$ & $\ldots$ & $\ldots$ & $\ldots$ & $\ldots$ & 8.28 & 4.82 & 2.47 & 0.001 \\
\hline 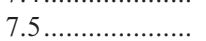 & $\ldots$ & $\ldots$ & $\ldots$ & $\ldots$ & $\ldots$ & 8.70 & 5.12 & 2.61 & 0.001 \\
\hline
\end{tabular}

\section{REFERENCES}

Arav, N., Kaastra, J., Steenbrugge, K., Brinkman, B., Edelson, R., Korista, K. T., \& de Kool, M. 2003, ApJ, 590, 174

Badnell, N. R., Pindzola, M. S., \& Griffin, D. C. 1990, Phys. Rev. A, 41, 2422

Bautista, M. A., Kallman, T. R., \& Pradhan, A. K., eds. 2000, Atomic Data Needs in X-Ray Astronomy (NASA/CP-2000-209968; Greenbalt: NASA)

Beiersdorfer, P., Schneider, M. B., Bitter, M., \& von Goeler, S. 1992, Rev. Sci. Instrum., 63, 5029

Bell, K. L., Gilbody, H. B., Hughes, J. G., Kingston, A. E., \& Smith, F. J. 1983, J. Phys. Chem. Ref. Data, 12(4), 891

Bell, R. H., \& Seaton, M. J. 1985, J. Phys. B, 18, 1589

Bely-Dubau, F., Dubau, J., Faucher, P., \& Gabriel, A. H. 1982, MNRAS, 198, 239

Berrington, K. A., Burke, P. G., Butler, K., Seaton, M. J., Storey, P. J., Taylor, K. T., \& Yu Yan. 1987, J. Phys. B, 20, 6379

Berrington, K. A., Eissner, W., \& Norrington, P. H. 1995, Comput. Phys. Commun., 92, 290

Cen, R., Tripp, T. M., Ostriker, J. P., \& Jenkins, E. B. 2001, ApJ, 559, 5

Eissner, W., Jones, M., \& Nussbaumer, H. 1974, Comput. Phys. Commun., 8,270

Fang, T., \& Canizares, C. R. 2000, ApJ, 532, 539

Gabriel, A. H. 1972, MNRAS, 160, 99

Hummer, D. G. 1994, MNRAS, 268, 109
Hummer, D. G., Berrington, K. A., Eissner, W., Pradhan, A. K., Saraph, H. E., \& Tully, J. A. 1993, A\&A, 279, 298

Kaastra, J. S., Mewe, R., Liedahl, D. A., Komossa, S., \& Brinkman, A. C. 2000, A\&A, 83, L354

Nahar, S. N. 1996, Phys. Rev. A, 53, 2417 1998, Phys. Rev. A, 58, 3766 1999, ApJS, 120, 131

Nahar, S. N., \& Pradhan, A. K. 1992, Phys. Rev. Lett., 68, 1488 1994, Phys. Rev. A, 49, 1816 1997, ApJS, 111, 339 (Paper I)

Nahar, S. N., Pradhan, A. K., \& Zhang, H. L. 2000, ApJS, 131, 375 (Paper IV)

- 2001, ApJS, 133, 255

Oelgoetz, J., \& Pradhan, A. K. 2001, MNRAS, 327, L42

Opacity Project Team. 1995, The Opacity Project, Vol. 1 (Bristol: Institute of Physics Publications)

Opacity Project Team. 1997, The Opacity Project, Vol. 2 (Bristol: Institute of Physics Publications)

Pequignot, D., Petitjean, P., \& Boisson, C. 1991, A\&A, 251, 680

Pradhan, A. K. 1985, ApJ, 284, 824

- 2000, ApJ, 545, L165

Pradhan, A. K., Chen, Guo Xin, Nahar, S. N., \& Zhang, H. L. 2001, Phys. Rev. Lett., 87, 183201

Pradhan, A. K., \& Zhang, H. L. 1997, J. Phys. B, 30, L571 
Sakimoto, K., Terao, M., \& Berrington, K. A. 1990, Phys. Rev. A, 42, 291

Savin, D. W. 1999, ApJ, 523, 855

Schippers, S., Bartsch, T., Brandau, C., Muller, A., Linkemann, J., Saghiri, A. A., \& Wolf, A. 1999, Phys. Rev. A, 59, 3092

Scott, N. S., \& Burke, P. G. 1980, J. Phys. B, 12, 4299

Scott, N. S., \& Taylor, K. T. 1982, Comput. Phys. Commun., 25, 347

Seaton, M. J. 1987, J. Phys. B, 20, 6363

Storey, P. J., \& Hummer, D. G. 1992, Comput. Phys. Commun., 66, 129
Verner, D. A., \& Ferland, G. 1996, ApJS, 103, 467

Wolf, A., et al. 1991, Z. Phys. D Suppl., 21, 569

Yoshikawa, K., Yamasaki, N. Y., Suto, Y. Ohashi, T., Mitsuda, K. Tawara, Y., \& Furuzawa, Y. 2003, in Workshop on Galaxies and Clusters of Galaxies (Tokyo: Japan Soc. for the Promotion of Science), 167

Zhang, H. L., Nahar, S. N., \& Pradhan, A. K. 1999, J. Phys. B, 32, 1459

Zhang, H. L., \& Pradhan, A. K. 1997a, Phys. Rev. Lett., 78, 195 1997b, J. Phys. B, 30, L571 